\title{
Ordered P3HT/PCBM Heterostructured Organic Photodiode for Radiation Detection using Direct Nanoimprint Lithography
}

\author{
Kazuhiro Tada ${ }^{1}$, Eiji Takada ${ }^{1}, \mathrm{~K}$ azuo $\mathrm{Fujii}^{1}{ }^{1}, \mathrm{~K}$ imiaki Uemura ${ }^{2}$, \\ Kohei T omohiro ${ }^{2}$ and $\mathrm{Y}$ oshihiko $\mathrm{Hirai}^{2}$ \\ ${ }^{1}$ Department of Electrical and C ontrol Systems Engineering, Toyama National College of Technology, \\ 13 Hongo-machi, Toyama, 939-8630 J apan \\ ${ }^{2}$ Department of Physics and Electronics Engineering, Graduate School of Engineering \\ 1-1,G akuen-cho, Nakaku, Sakai, 0 saka, 599-8531 J apan
}

\begin{abstract}
We propose an organic photodiode for radiation detection with nanoimprinted structure in $\mathrm{p}$ - $n$ junction to increase the $X$-ray induced current. It is found that the nanoimprited structure made from lower molecular weight P3HT, less than $90 \mathrm{~K} \mathrm{~g} / \mathrm{mol}$, is dissolved by the solvent of PCBM, that is, dichloromethane (DCM), on the other hand, the structure made from high molecular weight, $300 \mathrm{~K} \mathrm{~g} / \mathrm{mol}$, is not dissolved. The effect of expanding the $p-n$ junction using nanoimprint lithography is observed in the case of visible light and $X$-ray induced scintillation light irradiation.
\end{abstract}

\section{Keywords: Organic photodiode, Radiation detection, Thermal nanoimprint}

\section{Introduction}

In the field of radiation measurements, high efficient detector using inorganic semiconductors, such as silicon and germanium, has already been put to practical use. However, in these detectors, some calibration procedures are necessary to measure the correct energy transfer to body tissue, as their component is different from that of living body. Therefore, demands for new radiation detector are increasing in wide area of application.

Organic photodiode (OPD) made from organic semiconductor have excellent properties as bioequivalence with human body. Therefore, using OPDs as sensors to measure radiation is a desired application [1]. However, many technological challenges still exist. One of the big problems is that the amount of radiation induced current is far from practical use. As a solution, controlling the nanostructure in the device is needed to expand $p$-n junction, promote the exciton dissociation and increase the current.

Before now, two types of nanostructure are proposed in the OPD. One type is bulk heterojunction $(\mathrm{BHJ})[2,3]$, which is a random mixture of $p$ - and $n$-type organic semiconductor.
Although the morphology is optimized by experiment [4, 5] and simulation [6, 7], the theoretically random-ordered structure formed by the mixture of $p$ - and $n$ - type materials are not regularly connected to electrodes and leakage current is induced.

To compensate for any inconvenience, ordered heterojunction $(\mathrm{OHJ})$ is proposed as another type of nanostructure to eliminate leakage and also shorten the mean path to electrodes from the $p-n$ junction to decrease current loss. To fabricate the $\mathrm{OHJ}$ structure, the direct nanoimprint lithography $[8,9]$ has been demonstrated.

In organic photovoltaic cell using OPD, the conversion efficiencies of these two types of structures, that is, $\mathrm{BHJ}$ and $\mathrm{OHJ}$ are roughly the same level [10]. On the other hand, in the OPD for radiation detection, thicker device is more desirable to capture the $X$-ray because the penetrating power of $X$-ray is very high. As the $\mathrm{BHJ}$ device becomes thicker, the ability of charge transports decreases because the isolation parts increase. Therefore, there are the possibilities that the device with more stable charge transport pathway like $\mathrm{OHJ}$ is better suited for radiation 
detection.

In this work, as a first step to find out the optimum device structure, OPD for the radiation detection with $\mathrm{OHJ}$ structure is fabricated by direct nanoimprint lithography and the device performances are evaluated by irradiation of visible light and $X$-ray. In the $X$-ray irradiation experiments, we measured the current with and without a scintillator beneath the device.

\section{Fabrication process}

(a) Spi
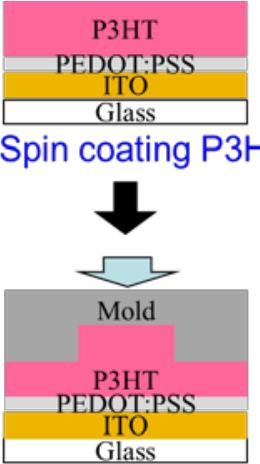

(b) Imprinting

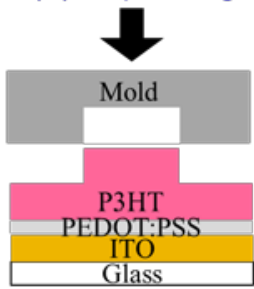

(c) Demolding
Spin coating P3HT

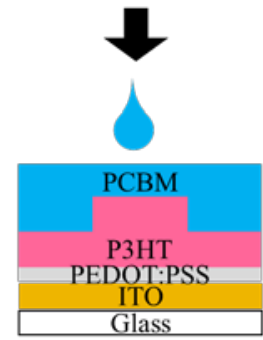

(d) Spin coating PCBM

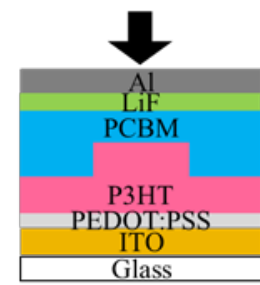

(e) Electrode deposition
Figure.1. Schematics of fabrication process.

Figure 1 shows typical process of ordered hetero junction $(\mathrm{OHJ})$ fabrication using direct nanoimprint and spin coating. At first, poly(3,4-ethylenedioxythiophene):poly(styrene sulfonate) (PEDOT:PSS) dissolved in ethyl alcohol was spin-coated onto indium-tin oxide (ITO) (150 $\mathrm{nm}$ thick) coated substrate at $2000 \mathrm{rpm}$ to a thickness of $30 \mathrm{~nm}$ and baked at $140{ }^{\circ} \mathrm{C}$ for $4 \mathrm{~min}$. (Fig. 1(a)) Then, P3HT dissolved in 1,2-dichlorobenzene (ODCB) was spin-coated and baked at $60{ }^{\circ} \mathrm{C}$ for $3 \mathrm{~min}$ to volatilize ODCB. After that, direct nanoimprint of P3HT was performed using conventional thermal nanoimprint equipment at $180{ }^{\circ} \mathrm{C}$. The applied pressure was 5 M Pa for 10 min using a Si mold. (Fig. 1(b)) After cooling to room temperature, the $\mathrm{Si}$ mold was released. (Fig. 1(c)) After removal of the mold, PCBM dissolved in dichloromethane (DCM) was spin-coated. (Fig. 1(d)) Then LiF and Al were deposited on PCBM by vacuum evaporation to thickness of 1 and $70 \mathrm{~nm}$, respectively. (Fig. 1(e))

Figure 2 shows the cross sectional images of imprinted P3HT (a) before and (b) after spin-coating PCBM. As shown in Fig. 2(a), line and space fine structure was successfully transferred. On the other hand, the fine structure was disappeared after spin-coating PCBM as shown in Fig. 2(b). Y. Y ang, et al. reported that lower molecular weight $\mathrm{P} 3 \mathrm{HT}$ is dissolved by the solvent of PCBM, that is, DCM, and P3HT fine structure disappears [10]. In the report, P3HT with high molecular weight more than $25 \mathrm{~K} \mathrm{~g} / \mathrm{mol}$ is not dissolved. However, the molecular weight of P3HT in this experiment is $80 \mathrm{~K}$ to $90 \mathrm{~K} \mathrm{~g} / \mathrm{mol}$. Therefore, contradictory result was obtained. In this study, we used the P3HT with higher molecular weight, 300 $\mathrm{K} \mathrm{g} / \mathrm{mol}$, which was made by SOKEN Chemical Co.

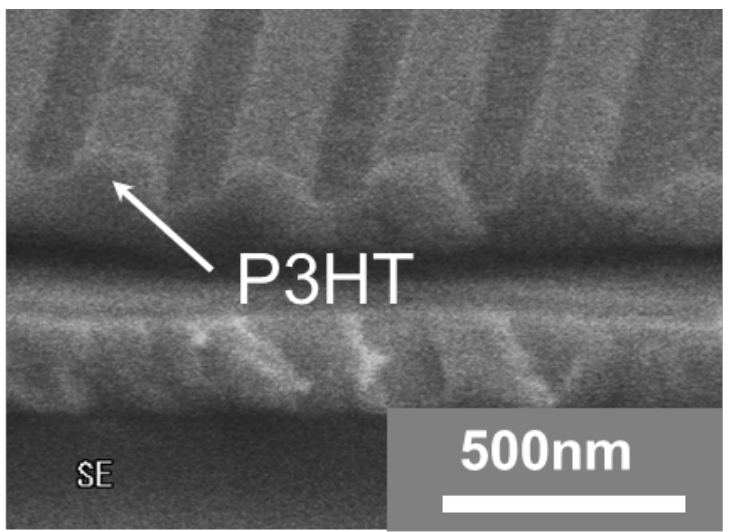

(a)

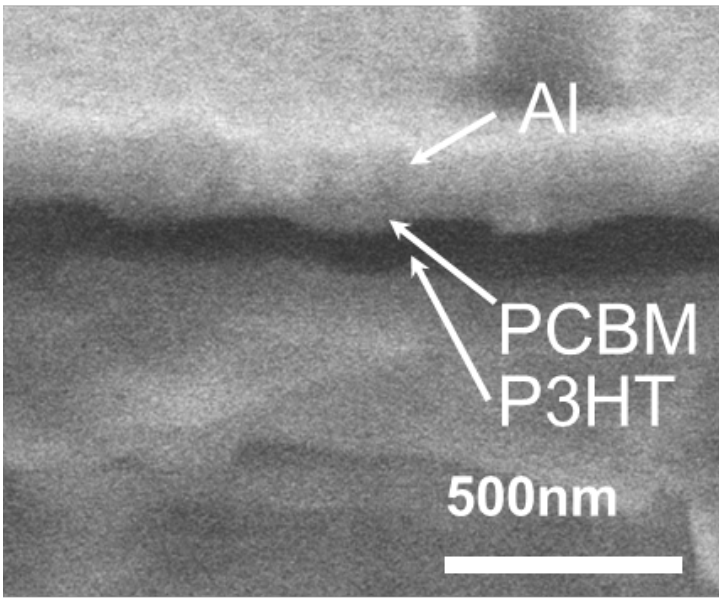

(b)

Figure.2. Cross sectional SEM images of imprinted $\mathrm{P} 3 \mathrm{HT}$ (a) before and (b) after spin-coating PCBM . 
Figure 3 shows the cross sectional views of nanoimprinted devices using $300 \mathrm{~K} \mathrm{~g} / \mathrm{mol}$ P3HT. Line width and height are $100 \mathrm{~nm}$. P3HT were imprinted at $180^{\circ} \mathrm{C}, 5 \mathrm{~min}$, and 5MPa. P3HT imprinted patterns was not dissolved and contrast of P3HT/PCBM interface is clear.

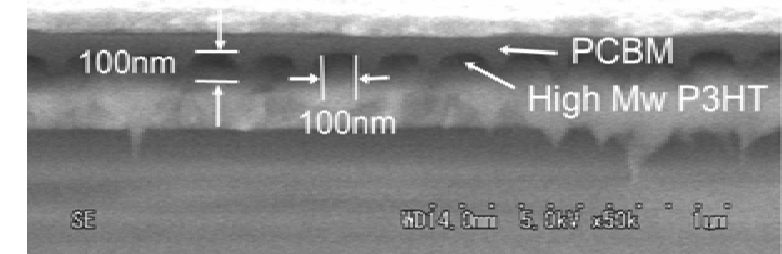

Figure.3. Cross sectional SEM image of ordered heterostructured organic photodiode.

\section{Experiments}

To evaluate the device performance in the visible light, we investigated the current-voltage (I-V) characteristics using a halogen lamp as a light source. Under irradiation of the light with the intensity of $50 \mathrm{~mW} / \mathrm{cm}^{2}$, the current was measured with the digital electrometer (ADCMT®, 8252). The active area of each device is the $4 \mathrm{~mm}^{2}$ crossed area of the upper and bottom electrodes.

In this work, four different samples were prepared as shown in Table 1. Two different thicknesses of P3HT (70 nm and $170 \mathrm{~nm}$ ) and two different interfaces of p-n junction (planar and ordered) were considered.

Table 1. Sample description.

\begin{tabular}{ccc}
\hline Sample & $\begin{array}{c}\text { Thickness of } \\
\text { P3HT }(\mathrm{nm})\end{array}$ & $\begin{array}{l}\text { p-n junction } \\
\text { interface }\end{array}$ \\
\hline A & 70 & Planar \\
B & 70 & Ordered \\
C & 170 & Planar \\
D & 170 & Ordered \\
\hline
\end{tabular}

\section{Results and Discussion}

The measured I-V characteristics are shown in Fig. 4. Table 2 summarizes the characteristics with open-circuit (Voc), short-current (Isc), fill factor (FF) and power conversion efficiency (PCE).

The devices with ordered interface (Sample B and D) had approximately $15 \%$ higher Isc than those with planar ones (Sample A and C) at each thickness. It is considered that the effect of expanding the $\mathrm{p}$-n interface appears. The devices with thinner P3HT (Sample A and B) had higher Isc than those with thicker P3HT (Sample C and
D). This is because charge transfer pathway of the devices with thinner P3HT is shorter than that with the thicker one.

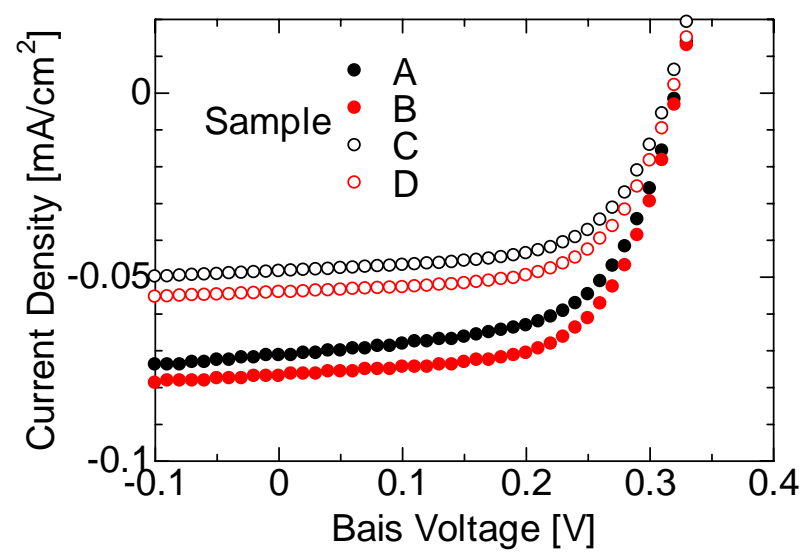

Figure 4. I-V characteristics of the planar and ordered devices under $50 \mathrm{~mW} / \mathrm{cm}^{2}$ using halogen lamp.

Table 2. Photovoltaic performance of the planar and ordered devices.

\begin{tabular}{ccccc}
\hline Sample & $\mathrm{V}_{\mathrm{oc}}(\mathrm{V})$ & $\mathrm{J}_{\mathrm{sc}}(\mathrm{mA})$ & $\mathrm{FF}$ & $\begin{array}{c}\mathrm{PCE} \\
(\%)\end{array}$ \\
\hline $\mathrm{A}$ & 0.33 & 0.071 & 0.59 & 0.027 \\
$\mathrm{~B}$ & 0.33 & 0.077 & 0.60 & 0.031 \\
$\mathrm{C}$ & 0.32 & 0.048 & 0.61 & 0.019 \\
$\mathrm{D}$ & 0.32 & 0.054 & 0.70 & 0.022 \\
\hline
\end{tabular}

The experimental setup for measuring the X-ray induced current is as follow. We measured the current using a digital electrometer connected to the device with a triaxial cable. In the experiment, OPDs were used without any supplied bias. Each OPD device was encapsulated in an aluminum box that provided electromagnetic shielding. X-rays from the X-ray generator (GE Sensing \& Inspection Technologies, 160MF4) were produced at an acceleration voltage of $50 \mathrm{kV}$. The shield box was open on the side which faced the $\mathrm{X}$-ray generator to irradiate the $\mathrm{X}$-rays without any attenuation.

Figure 5 shows the $\mathrm{X}$-ray induced current for OPD under X-ray irradiation without a scintillator.

The devices with ordered interface (Sample D) had approximately $10 \%$ higher X-ray induced current than those with planar ones (Sample C). It is considered that the effect of expanding the p-n interface appears. However, in Sample A and B, the effect was not appeared. At this moment, the reason is still unknown and more detailed 
investigations are needed. The devices with thinner P3HT (Sample A and B) had higher Isc than those with thicker P3HT (Sample C and D) as in the cases of visible light irradiation.

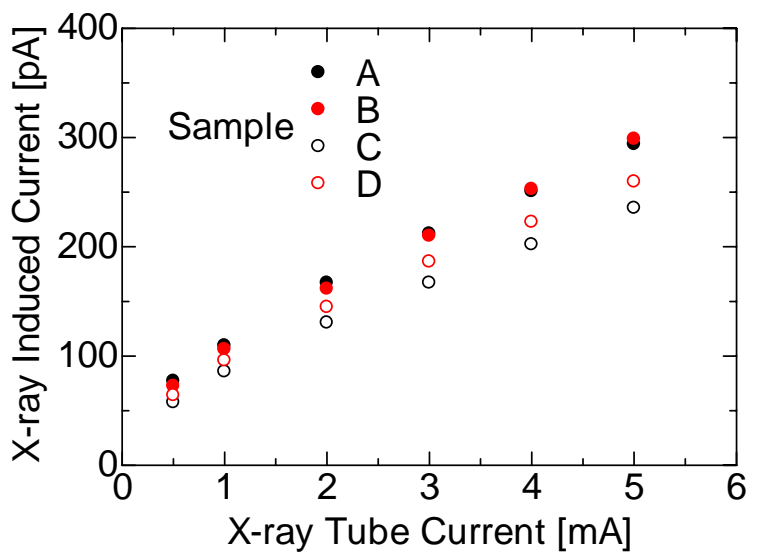

Figure 5. X-ray induced current for OPD under X-ray irradiation without a scintillator.

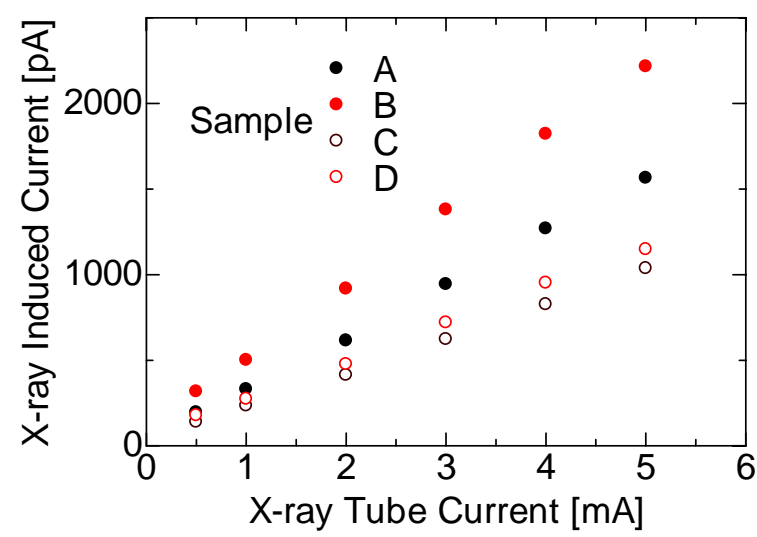

Figure 6. X-ray induced current for OPD combined with a scintillator.

Figure 6 shows the $\mathrm{X}$-ray induced current for OPD combined with a scintillator. The devices with ordered interface (Sample B and D) had 20 to $50 \%$ higher Isc than those with planar ones (Sample A and C) at each thickness for the similar reason with the two cases described above. The devices with thinner P3HT (Sample A and B) had higher Isc than those with thicker P3HT (Sample C and D). These results show the same tendency of those obtained under visible light irradiation.

\section{Conclusions}

Organic photodiode for radiation detection with nanoimprinted structure in p-n junction was newly proposed to increase the X-ray induced current.

In the fabrication process, it is found that the nanoimprited structure made from lower molecular weight P3HT, less than $90 \mathrm{~K} \mathrm{~g} / \mathrm{mol}$, is dissolved by the solvent of PCBM, that is, DCM, on the other hand, the structure made from high molecular weight, $300 \mathrm{~K} \mathrm{~g} / \mathrm{mol}$, is not dissolved.

The device performances with thinner P3HT increase in every case of the irradiation, that is, visible light irradiation, X-ray irradiation with and without a scintillator.

The effect of expanding the p-n junction using nanoimprint lithography was observed in the case of visible light irradiation and X-ray irradiation with a scintillator, on the other hand, the effect is not observed so much in the case of X-ray irradiation without a scintillator.

In the future work, we evaluate the relationship between the structure of $p-n$ junction and the device performance more quantitatively.

\section{References}

1) E. Takada, A. Takada, A. Inoue, H. Imai, H. Okada, S. Naka, J. Kawarabayashi, T. Nakamura and Y. Namito, J. Nucl. Sci. Technol., 48 (2011) 1140.

2) G. Yu, J. Gao, J. C. Hummelen, F. Wudl, and A. J. Heeger, Science, 270 (1995) 1789.

3) N. S. Sariciftci, L. Smilowitz, A. J. Heeger, and F. Wudl, Science, 258 (1992) 1474.

4) G. Li, V. Shrotriya, Y. Yao, and Y. Yang, Appl. Phys., 98 (2005), 043704 (2005).

5) Y. C. Huang, Y. C. Liao, S. S. Li, M. C. Wu, C.W. Chen, and W. F. Su, Sol. Energy Mater., 93 (2009), 888.

6) B. Ray, P. R. Nair, and M. A. Alam, Sol. Energy Mater., 95 (2011), 3287.

7) B. Ray and M. A. Alam, Sol. Energy Mater. Sol. Cells, 99 (2012) 204.

8) S. Y. Chou, P. R. Krauss, and P. J. Renstrom, Appl. Phys. Lett., 67 (1995) 3114.

9) M. Colburn, S. Johnson, M. Stewart, S. Damle, T. Bailey, B. Choi, M. Wedlake, T. Michaelson, S.V. Sreenivasan, J. Ekerdt, and C. G. Willson, Proc. SPIE, 3676 (1999) 378.

10) Y. Yang, K. Mielczarek, M. Aryal, A. Zakhidov, and W. Hu, ACS Nano, 6 (2012) 2877. 